\title{
A Comparative Study of Retinal Image Processing Technique for Blood Vessel Segmentation
}

\author{
Shreyasi Hazra ${ }^{1}$, Atashi Patra ${ }^{2}$, Tuhin Utsab Paul ${ }^{3}$ \\ 1, 2 Student, Electronics and Communication Engineering, Institute of Engineering \& Management Kolkata, India \\ ${ }^{3}$ Assistant Professor, Electronics and Communication Engineering, Institute of Engineering \& Management, Kolkata, India
}

\begin{abstract}
Blood vessel assessment from retinal images is an important factor for many eye related disease. Retinal blood vessel segmentation is done for identifying ophthalmic disease like glaucoma, diabetic retinopathy, and macular degeneration. Glaucoma is a condition of elevated pressure within the eyeball, which causes gradual loss of sight. Diabetic retinopathy occurs due to damage of the tiny blood vessels that nourish the retina. It results in blood and other fluids leakage that swells retinal tissue that causes clouding of vision. Macular Degeneration happens when central portion of the retina deteriorates. Thus, blood vessel segmentation efficiently reduces the risk of blindness. The manual comparison of fundus images taken at different moments is a very time-consuming job and prone to human error because of the distortions between images that make superposition very difficult, and also there are large numbers of lesions that need to be compared. Hence, computer assisted approach is needed. We have compared different methods of retinal blood vessel segmentation based on parameters like accuracy, sensitivity, specificity and algorithms that have been used for blood vessel segmentation method.
\end{abstract}

Keywords: Retinal Blood vessel segmentation, Optic Disc, Accuracy, Specificity, Sensitivity

\section{Introduction}

The involvement of image processing in diabetic retinopathy diagnosis may be divided into the following three groups: Image enhancement, Mass screening, Monitoring of the disease [1].

Existing method of blood vessel identification and segmentation requires large amount of time and manual intervention, and it might be prone to human error. Hence, automatic blood vessel detection is required for efficiently detecting blood vessels. In addition to automatic detection of blood vessels, this kind of automated tool needs a strong feature-based registration algorithm [1] for segmentation of blood vessels in retina. This has been a research area, for years. Registration algorithms for retinal images have been proposed in [2]-[4].

However, there are two major problems in segmenting retinal blood vessels, for example, a) presence of large variety of vessel widths and b) the heterogeneous background of the fundus image [5]. Hence, the images are needed to be pre-processed. The images are taken from DRIVE [6] and STARE [7] database [8]. The DRIVE database has been established to enable comparative studies on segmentation of blood vessels in retinal images. The STARE (STructured Analysis of the Retina) is database where retinal interior surface picture are saved. Originally, the STARE database was collected by Hoover et al. [9]. The DRIVE database contains 40 images which include 20 in test set, 20 in training set. Blood segmentation algorithms are performed on test set. The STARE database contains 20 images, out of which 10 are used for pathological purpose [10].

The images are then converted to appropriate color space first and then filtering and histogram equalization techniques are applied to the images. After pre-processing, the images are ready for segmentation. There are various segmentation methods for segmenting the retinal vessels in the fundus image which segments the retinal vessels using mathematical morphology, k-means or c-means algorithm [11]. After detecting and segmenting the blood vessels, various performance measurements like accuracy, specificity, sensitivity are done to measure the efficiency of the proposed algorithm.

Here, we will discuss different process/algorithms used in the existing works to segment hard exudates from retina and compare them based on different parameters.

\section{Theory}

The general flow chart for the optic disc detection and blood vessels detection is shown in figure 1 :

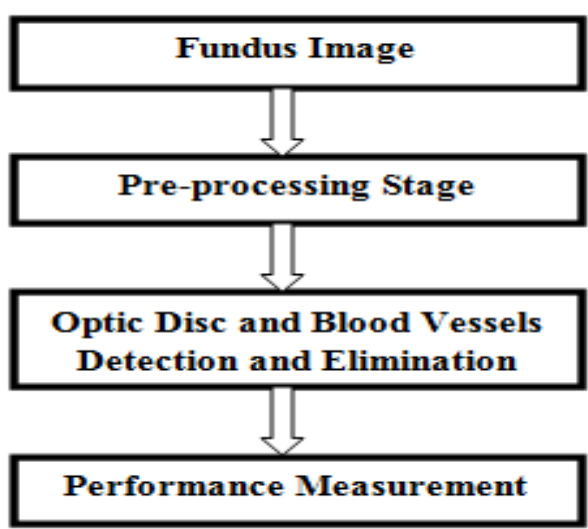

Figure 1: General Flow chart for optic disc and blood vessel detection

A.Pre-Processing Stage

a)Image Acquisition: Non-mydriatic retinal fundus camera is used to take all digital retinal images from patients. In the pre-processing stage, the original RGB image is 


\section{International Journal of Science and Research (IJSR) \\ ISSN (Online): 2319-7064}

Index Copernicus Value (2013): 6.14 | Impact Factor (2015): 6.391

transformed into appropriate colour space for further processes. And then, filtering technique is used to diminish the effect of noise. After using the filtering technique, the noise such as salt and pepper noise are removed from the image. Then contrast-limited adaptive histogram equalization (CLAHE) is used for image enhancement.

b) RGB to HSI conversion: In digital image, the input image can be in RGB (Red, Green, and Blue) format or other. The RGB image can be described as $\mathrm{M}$ x N x 3 array of colour pixels. The input image is transformed into HSI colour space for further processing.

c)Filtering Techniques: Noise can cause trouble disease detection. The noise in the image is reduced by using the filtering technique. Median Filter, Averaging filter, Wiener filter are different filtering techniques used for filtering. However, the median filter produces best output in reducing the effect of noise. And also, it can reduce the noise without blurring the edge. Therefore, the median filter is chosen for the filtering the image.

d)Image Enhancement: The result image of the median filter is then enhanced by using the histogram equalization technique. The histogram equalization technique is used to diminish the uneven-illumination case. There are two methods to enhance the image: Histogram equalisation and Adaptive histogram equalisation.

\section{B.Optic Disc and Blood Vessels Detection And Elimination}

There are many methods to detect the optic disc and the blood vessels, such as K-means clustering algorithm, Fuzzy C means, Mathematical Morphology and so on.

a) Mathematical Morphology: The basic mathematical morphology operators include the following: Dilation, Erosion, Closing, and Opening. Dilation adds pixels to the boundaries of objects in an image. Erosion removes pixels on object boundaries. The number of pixels added or removed from the objects in an image depends on the size and shape of the structuring element used to process the image. Opening is performed by doing erosion followed by dilation using structuring element. Closing is done by performing dilation followed by erosion using same structuring element. These are used to remove small holes.

b)Fuzzy C Means: In pattern recognition, Fuzzy C-Means (FCM) method is widely used for clustering. FCM based segmentation is fuzzy pixel classification. In this clustering technique one piece of data may belong to two or more clusters. FCM allows data points or pixels to belong to multiple classes where membership function of data points varies between 0 and 1. FCM computes cluster centres or centroids by reducing the dissimilarity function with the help of iterative approach. By updating the cluster centres and the membership grades for each pixel, the cluster centres shifts to the "right" location within set of pixels in FCM.

c)K Means Algorithm: The aim of k-means algorithm is to make a partition of objects into several classes and to make the distances between objects of same class closer than the distances between objects of different classes. So if certain centroids in which individual centroids represents a group of similar objects can be obtained, the centroids consistent with the distribution of data can be found.

d)Region Growing: The final image with the segmented vessels is obtained using iterative approach by combining the centreline images with the image that resulted from the segmentation part. For a region growing algorithm, vessel centreline pixels are used as primary points, which fill these points by aggregation of the pixels in the segmentation image.

\section{C.Performance Measurement}

First, the hand drawn ground truth from ophthalmologists is obtained and it is compared with the segmented result from automatic tool. Thus, True positive, true negative, false positive and false negative values are measured. Based on these values, accuracy, specificity, sensitivity, Positive Likelihood ratio (PLR), Positive Predictive Value (PPV) is obtained to measure the performance efficiency of the proposed algorithm.

\section{Parameter Description}

- True positive $(\mathrm{TP})=$ The portion of image which are correctly identified

- False positive $(\mathrm{FP})=$ The portion of image which are incorrectly identified

- True negative $(\mathrm{TN})=$ The portion of image which are correctly rejected

- False negative $(\mathrm{FN})=$ The portion of image which are incorrectly rejected

- Accuracy is a level of measurement that yields true (no systematic errors) and consistent (no random errors) results. That is, the accuracy is the proportion of true results (both true positives and true negatives) among the total number of cases observed.

Accuracy $=(\mathrm{TP}+\mathrm{TN}) /(\mathrm{TP}+\mathrm{TN}+\mathrm{FP}+\mathrm{FN})$

- Sensitivity (also called the true positive rate, or the recall in some fields) measures the proportion of positives that are correctly identified, that is, fraction of relevant instances that are retrieved.

Sensitivity $=\mathrm{TP} /(\mathrm{TP}+\mathrm{FN})$

- Specificity (also called the true negative rate) measures the proportion of negatives that are correctly identified Specificity $=\mathrm{TN} /(\mathrm{TN}+\mathrm{FP})$

- PPV (Positive Predictive Value) is proportion of positive results in statistics and diagnostic tests that are true positive. It is the fraction of retrieved instances that are relevant. PPV $($ Positive Predictive Value $)=\mathrm{TP} /(\mathrm{TP}+\mathrm{FP})$

- PLR (Positive Likelihood Ratio): Likelihood ratios are used for assessing the value of performing a diagnostic test. They use the sensitivity and specificity of the test to determine whether a test result usefully changes the probability that a condition (such as a disease state) exists. The positive likelihood ratio is calculated as

○ PLR = Sensitivity / ( 1 - Specificity $)$

o Hence, PLR (Positive Likelihood Ratio) =

$\circ[\mathrm{TP} /(\mathrm{TP}+\mathrm{FN})] /[\mathrm{FP} /(\mathrm{FP}+\mathrm{TN})]$ 


\section{Descriptive Study of Few Existing Works}

\subsection{FCM based blood vessel segmentation method for retinal image}

In this paper [5], the authors Nilanjan Dey et al. converted the colour retinal fundus image from green channel into gray scale image. Then, Adaptive histogram equalization is performed on the gray image.

After that, median filtering technique is used to subtract background from the foreground of the image. Then, FCM is carried out on the image which follows binarization and filtering. Finally, the ground truth image has been compared with the corresponding result and sensitivity, specificity, PPV, PLR and accuracy have been measured.

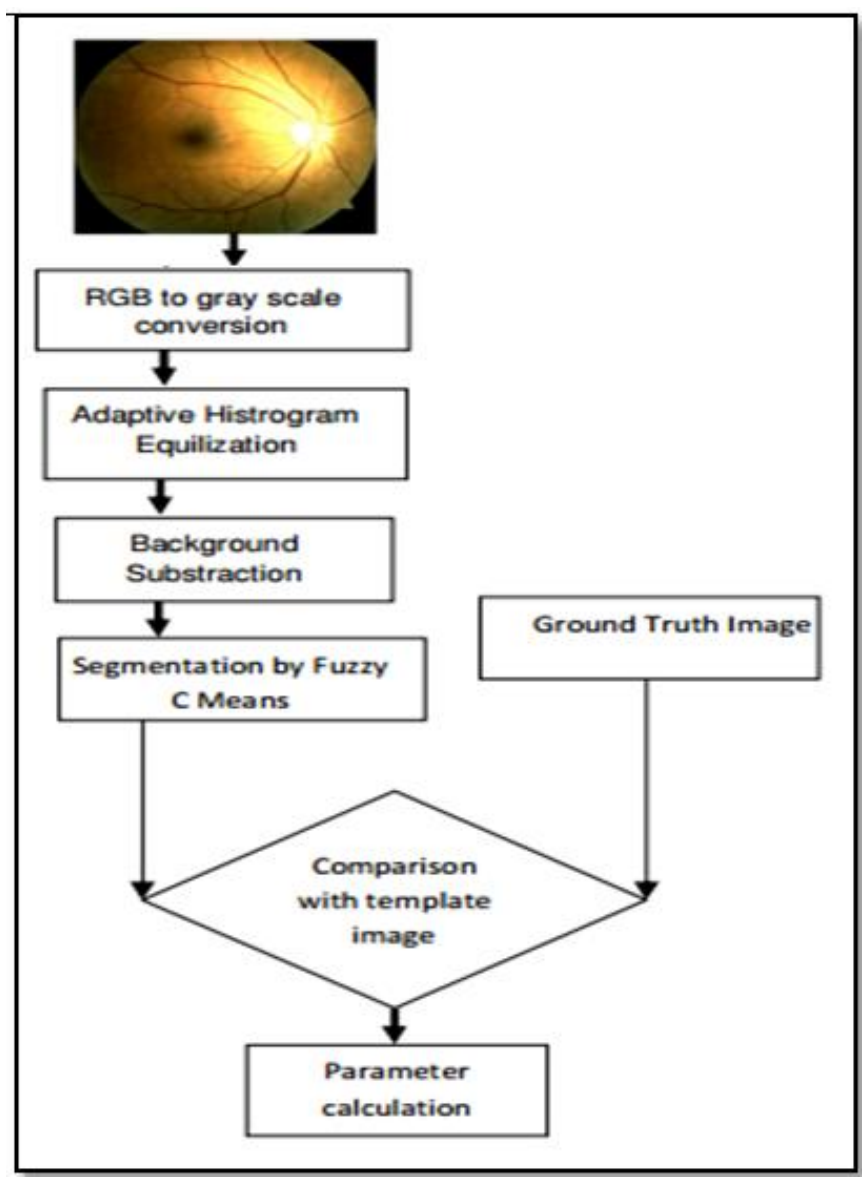

Figure 2: Blood vessel segmentation method proposed by Nilanjan Dey et al. [5]

The output of the proposed algorithm is shown in figure 3 .

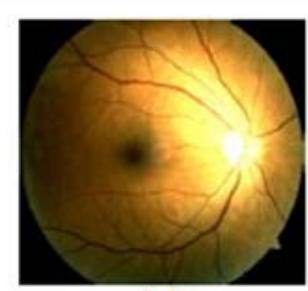

(a)

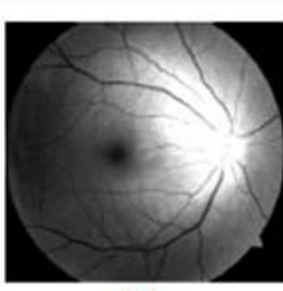

(b)

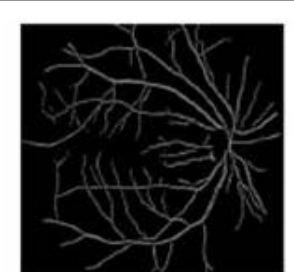

(c)

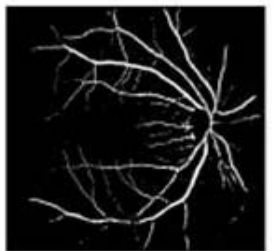

(d)

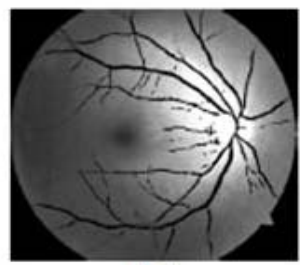

(e)

Figure 3: (a) Original image, (b)Gray scale image , (c) Hand drawn - gound truth" (d) Detected Blood Vessel using proposed method (e) Blood vessel detected Image. [5]

This proposed algorithm has yield very good performance where accuracy (95.03\%) is good. Also, it produced high sensitivity (99.62\%), high PPV (95.08\%), high PLR (219.72). Here, FCM helps to increase the prominence of every finer detail of blood vessels irrespective of thick or thin.

However, Specificity ( $54.66 \%$ ) is not up to the mark in this algorithm. The disadvantage of the Fuzzy $\mathrm{C}$ means is that, for noisy images it does not take into account spatial Information, which makes it sensitive to noise \& other image artifacts based on distribution of pixel intensity, so it is sensitive to intensity variations in the illumination.

\subsection{Automatic detection of diabetic retinopathy exudates from non-dilated retinal images using mathematical} morphology methods

In this paper [12], Akara Sopharak et al. proposed the following steps for detecting exudates, shown in figure 4: 


\section{International Journal of Science and Research (IJSR) \\ ISSN (Online): 2319-7064}

Index Copernicus Value (2013): 6.14 | Impact Factor (2015): 6.391

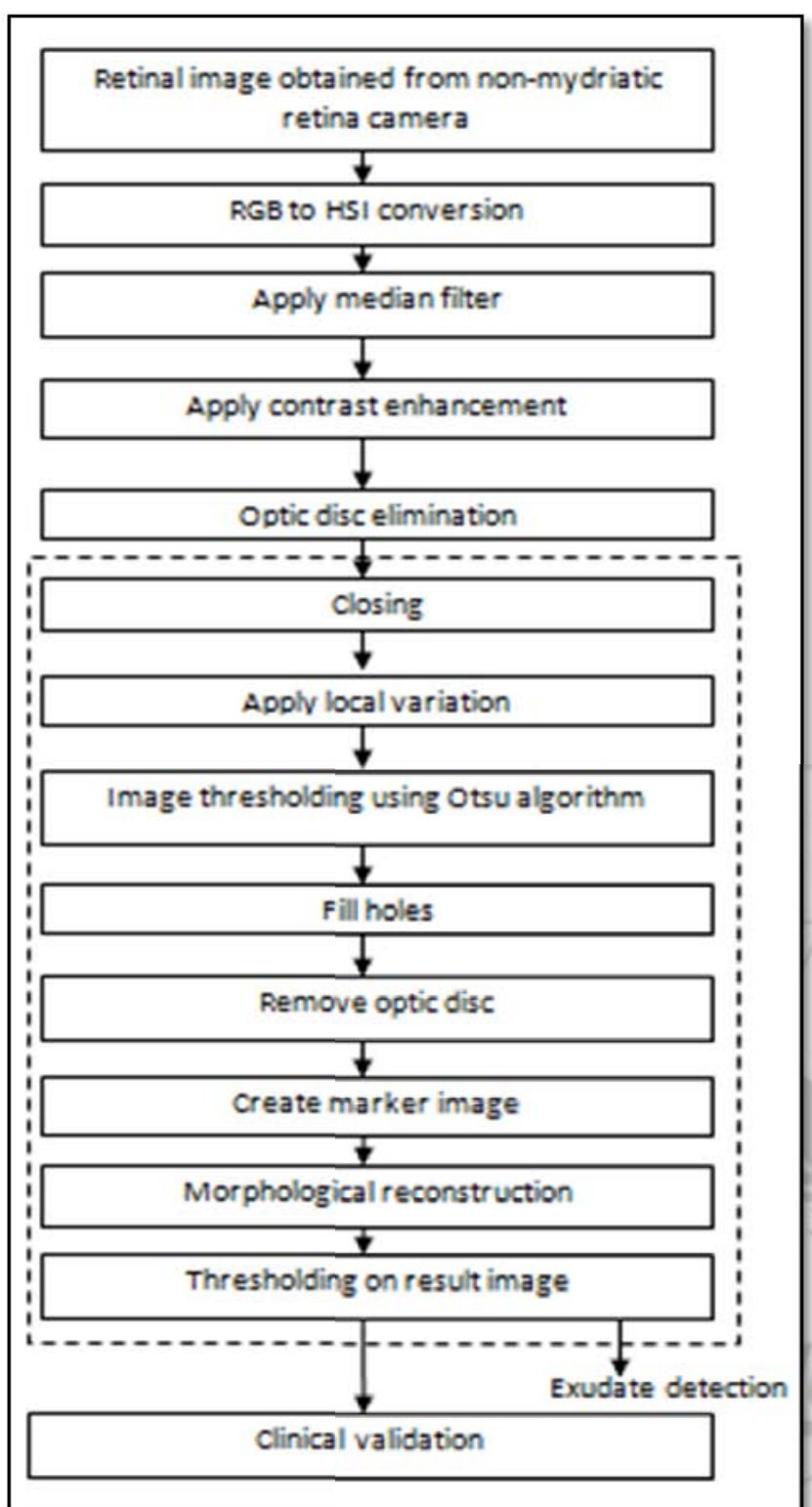

Figure 4: Proposed exudates detection by Akara Sopharak et al. [12]

Firstly, the RGB space of the original image was converted to HSI space because HSI colour space is more appropriate since it allows the intensity component to be separated from the other two colour components. Then, median filtering operation was applied to reduce noise. After that, contrastlimited adaptive histogram equalization (CLAHE) was applied for contrast enhancement. After performing the equalizations, bilinear interpolation was used to combine the neighbouring small regions.

Secondly, optic disc was eliminated prior to the process because it appears with similar intensity, colour contrast to other features on the retinal image. The optic disc is categorized by the largest high contrast among circular shape areas.

Finally, exudates are detected. In this step, the resulting image was thresholded at automatically selected grey levels, using the Otsu algorithm, to get rid of all regions with low local variation. A binary dilation operator was also applied with a flat disc-shaped structuring element with a fixed radius to ensure that all the neighbouring pixels of the thresholded result were also included in the candidate region. The output is shown in figure 5.
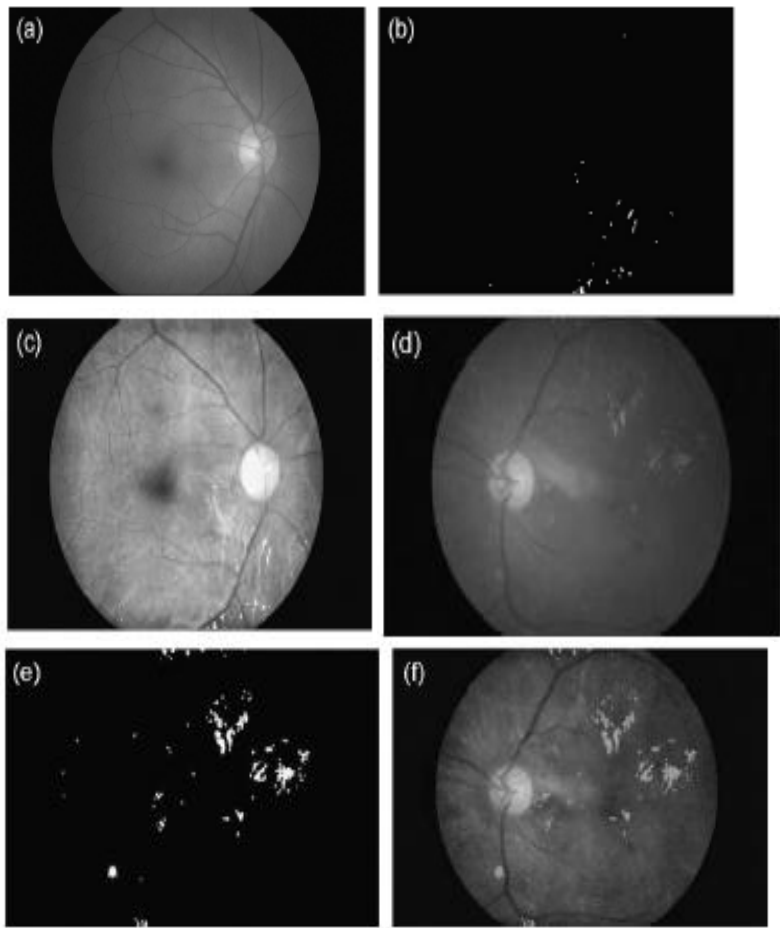

Figure 5: (a) Original images of a normal eye; (b) detected structures of (a); (c) detected structures superimposed on contrast enhanced images; (d) Original images of a diseased eye; (e) detected exudates of (d); (f) detected exudates superimposed on contrast enhanced images. [12]

This algorithm produces very good accuracy 96.79\%), very high specificity (99.46\%). This method was developed to detect exudates from non-mydriatic, low-contrast, retinal digital images of retinopathy patients.

However, sensitivity (80\%) is not up to the mark, also PPV (68.56\%) is on lower side and PLR (54.92) is very low. It has $52.36 \%$ of misclassified proportions. There are also some incorrect exudate detections due to artefacts that are similar to exudates, artefacts from the noise in the image acquisition process, the exudates which are adjacent to blood vessels or because the exudates appear very faded.

\subsection{Automatic Exudate Detection from Non-dilated Diabetic Retinopathy Retinal Images Using Fuzzy C means Clustering}

In this paper [13], the authors Akara Sopharak et al. firstly identified exudates on the ophthalmoscope as areas those are of hard white or yellowish colours with heterogeneous sizes, shapes and locations. Then the coarse segmentation was performed using Fuzzy C Means clustering. Afterwards, the feature were selected is based on the intensity value after pre- processing, standard deviation of intensity, hue and number of edge pixels from an edge image. The result from the previous section is a coarse estimation of the exudates. In order to get a better result, a fine segmentation is applied using morphological reconstruction. Finally, after fine segmentation, performance of each parameter like accuracy, specificity, sensitivity was measured by comparing the

\section{Volume 5 Issue 4, April 2016}




\section{International Journal of Science and Research (IJSR) \\ ISSN (Online): 2319-7064}

Index Copernicus Value (2013): 6.14 | Impact Factor (2015): 6.391

detection results with ophthalmologists' hand drawn ground truth.

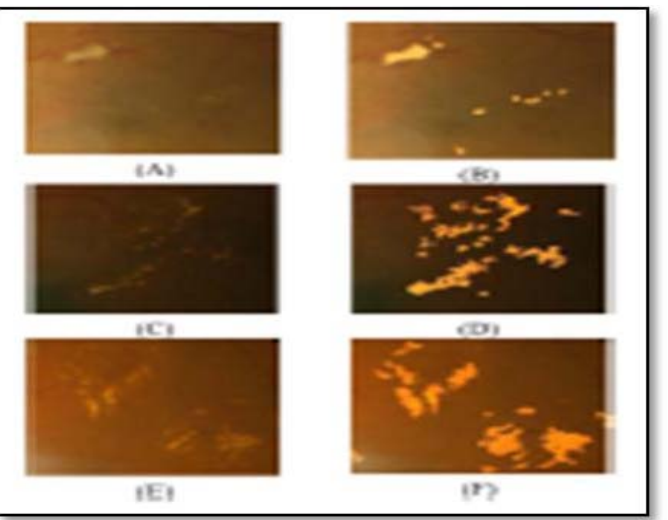

Figure 6: Exudates detection on low contrast images (A), (C) and (E) are original images, (B), (D) \& (F) are detected exudates superimposed on original images of (A), (C) and

(E) respectively. [13]

This algorithm yielded very good accuracy (99.11\%), very high specificity (99.24\%) and good PLR (224.26). It produced moderate $87.28 \%$ and low PPV (42.77\%). FCM clustering technique is combined with morphological technique to increase PPV, PLR and accuracy values. Blood vessels and optic disc pixels are also removed to avoid misclassification.

However, there are some improper exudate detections which are caused by the artifacts similar to exudates, artifacts which resulted from noise in the image acquisition process or the exudates that are adjacent to blood vessels or pale exudates.

\subsection{A Novel Retinal Blood Vessel Segmentation Algorithm using Fuzzy segmentation}

In this paper [14], Razieh Akhavan et al. proposed below algorithm for segmenting blood vessel, shown in figure 7 :

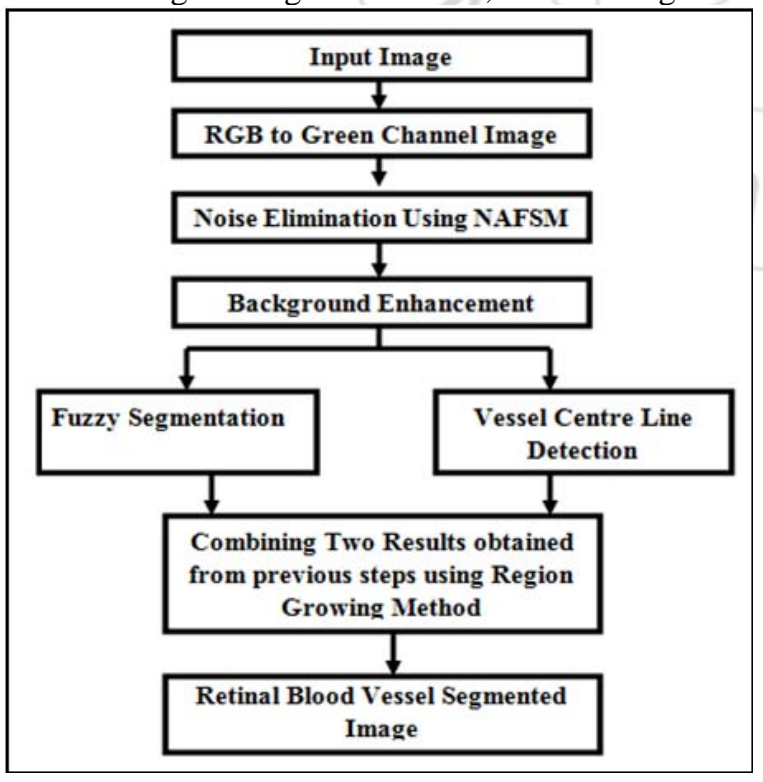

Figure 7: Proposed algorithm for Retinal vessel segmentation functional diagram by Razieh Akhavan et al. [14]
The retinal blood vessel information in the green channel image is clearer and provides better contrast between the image and the background, hence, the RGB fundus image was converted to green channel image to make the segmentation process easier and to reduce the computational time. If a noise was detected in image, the noise used to be eliminated using Noise Adaptive Fuzzy Switching Median Filter (NAFSM). After this step, retinal vessels needed to be filled starting from the detected centre-lines to achieve a complete segmentation. For this, the author used fuzzy Cmeans clustering technique. The final image after the vessel segmentation is obtained by combining the centre-line images with the image resulted from the fuzzy segmentation part in iterative approach. For region growing, vessel centreline pixels are used as primary points which fill these points by combining the pixels in the fuzzy segmentation image.

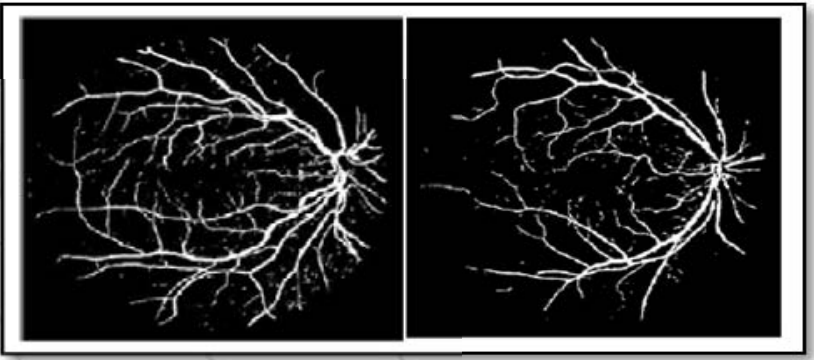

Figure 8: Two examples of segmented images from DRIVE database [14]

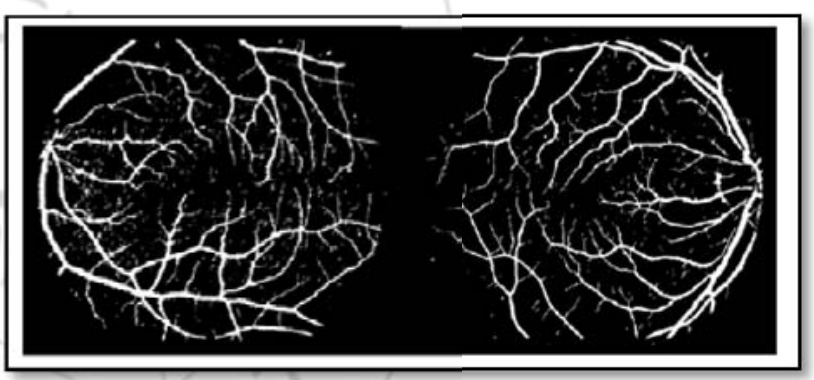

Figure 9: Two examples of segmented images from STARE database [14]

This algorithm yields good Sensitivity [97.33\% for Drive database \& 96.80\% Stare database] and good Specificity [95.13\% for Drive database \& 95.3\% Stare database]. Also, Noises are removed from retinal images using Adaptive Fuzzy Switching Median filter. CLAHE technique is used to implement the contrast enhancement.

Though, accuracy [72.52\% Drive database \& 77.6\% Stare database] is not satisfactory. Also, this method can extract the vessel centres entirely, but not the actual width of the vessels. Here, PPV and PLR values are not mentioned.

\subsection{A Contribution of Image Processing to the Diagnosis of Diabetic Retinopathy-Detection of Exudates in Color Fundus Images of the Human Retina}

In this paper [1], Thomas Walter et al. has performed the following steps for detection of optic disc and exudates:

Morphological filtering techniques and active contours are used to find out the boundary of the optic disc. An area threshold is used to localize the optic disc and the water-shed transformation is used to detect its contours. After this,

\section{Volume 5 Issue 4, April 2016}




\section{International Journal of Science and Research (IJSR) \\ ISSN (Online): 2319-7064 \\ Index Copernicus Value (2013): 6.14 | Impact Factor (2015): 6.391}

colour normalization and local contrast enhancement is performed. For blood vessel segmentation, Fuzzy C Means clustering algorithm is used. Finally, neural networks are used for the final classification. Figure 10 shows the segmentation algorithm proposed by Thomas Walter et al.

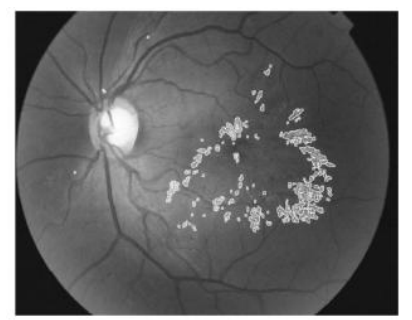

Figure 10: Result of the segmentation algorithm proposed by Thomas Walter et al [1]

Sensitivity (92.8\%) is measured moderately and PPV (92.4\%) is good for this proposed algorithm. Here, accuracy, specificity and PLR are not measured.

\subsection{Automatic exudate detection for diabetic retinopathy screening}

In paper [15], the steps followed by Akara Sopharaka et al. to automatically detect exudates are exudate detection, feature extraction, segmentation using FCM clustering and finally performance measurement.

Firstly, exudates were identified on the ophthalmoscope as white or yellowish areas with different sizes, shapes, and locations.
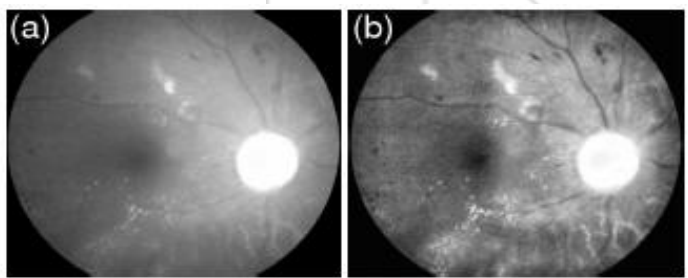

Figure 11: Pre-processing result: (a) original I band (b) I band after pre-processing. [15]

After detection, four features were experimentally taken out as input for FCM clustering. They were the intensity value after pre-processing, the standard deviation of intensity, the hue, and the number of edge pixels from an edge image. As intensity can be used to distinguish exudate pixels from normal pixels, the intensity of the image after pre-processing (ICLAHE) was selected as one of the classification features. Firstly, the RGB image was transformed to HSI space, shown in figure 12. A median filtering operation was then applied to lessen noise. After that, a contrast-limited adaptive histogram equalization (CLAHE) was applied for performing contrast enhancement.
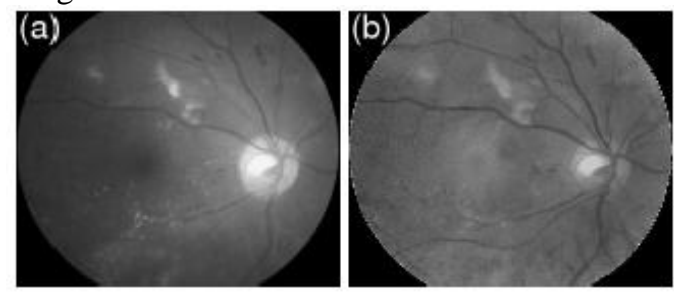

Figure 12: Hue Result: (a) Original RGB image (b) Hue image [15]

A number of edge pixels were selected as last feature because exudates gather together in tiny clusters normally, so they tend to have many edge pixels around the area.
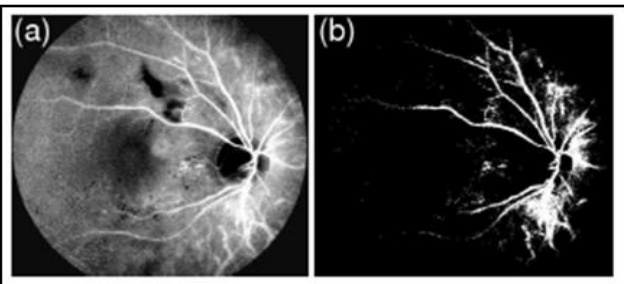

Figure 13: Blood vessel detection: (a) de-correlation stretch image on red plane (b) Blood vessel detected from de correlation stretch image. [15]

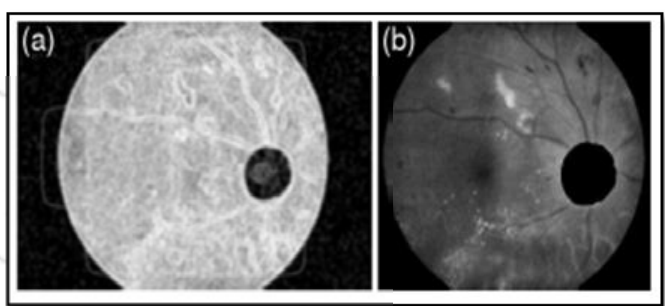

Figure 14: Optic disc detection: (a) entropy image (b) optic disc area eliminated from the contrast-enhanced image [15]

Finally, the image was segmented using FCM clustering. The output of FCM clustering is shown in figure 15. Features with a high similarity in an image were clubbed into the same cluster. The cluster centre was then calculated and updated until the difference between the objective function at consecutive iteration becomes less than a criterion provided previously.

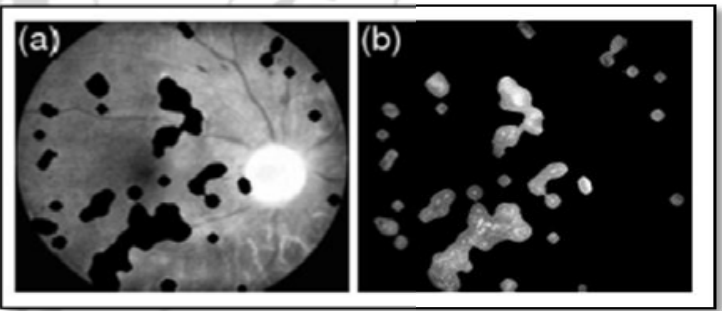

Figure 15: FCM clustering results with $n=2$ : (a) Cluster 1 (b) Cluster 2. [15]

Then, performance of each parameter was measured by comparing the detection results with ophthalmologists' hand drawn ground truth and sensitivity, specificity values were measured.
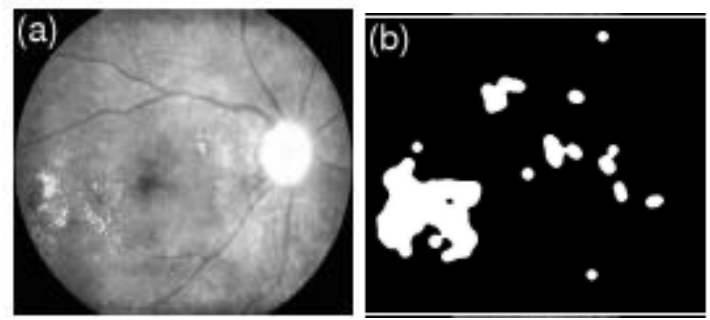


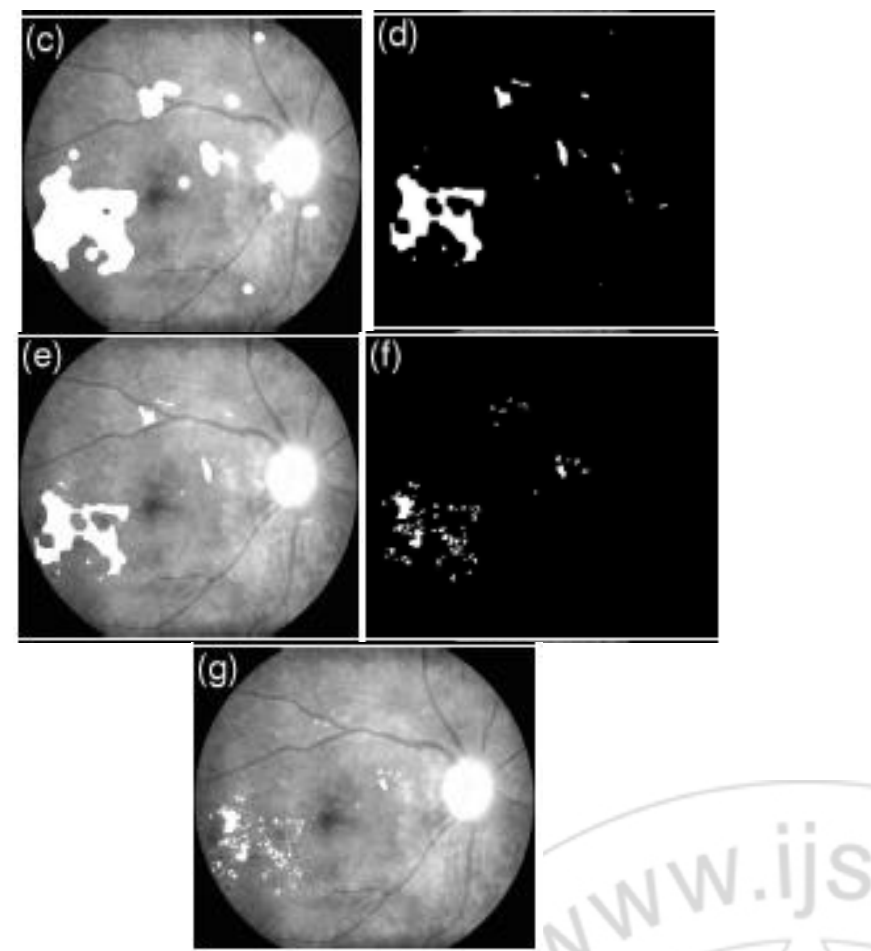

Figure 16: (a) Intensity image after pre-processing;

(b) Detected results using subtracted cluster (with $n=2$ );

(c) Result of (b) superimposed on the original image;

(d) Detected results using second cluster (with $n=8$ );

(e) Result of (d) superimposed on the original image;

(f) Corresponding ground truth images;

(g) Ground truth superimposed on the original image. [15]

This algorithm has used Improved FCM (IFCM). It has yield very high true positive value. Sensitivity was very good (97.29\%) and specificity (85.43\%) was measured moderately. But, the false positive value was very high due to misclassified non-exudate pixels. Also, accuracy, PPV and PLR values are not mentioned.

\subsection{Segmentation of Exudates and Optic Disc in Retinal Images}

In this paper [16], Giri Babu Kande et al. proposed the algorithm to confine the optic disc in ocular fundus images. Firstly, the optic centre was detected by finding the centre or region with maximum local variance. Then, the original image was pre-processed using colour morphology to eliminate blood vessels cleanly and to provide a more homogeneous optic disc region. Thirdly, the optic disc boundary was detected by fitting a geometric active contour model with variational formulation. In next step, the exudates were detected. Firstly, the retinal images are Preprocessed to enhance the contrast and the overall colour saturation in the image. Then, the optic disk is categorized by the maximum contrast area. Entropy feature on contrast enhanced image was used to roughly identify the optic disc. Next Spatially Weighted Fuzzy c-Means clustering was used to segment the exudates. The result is shown in figure 17.

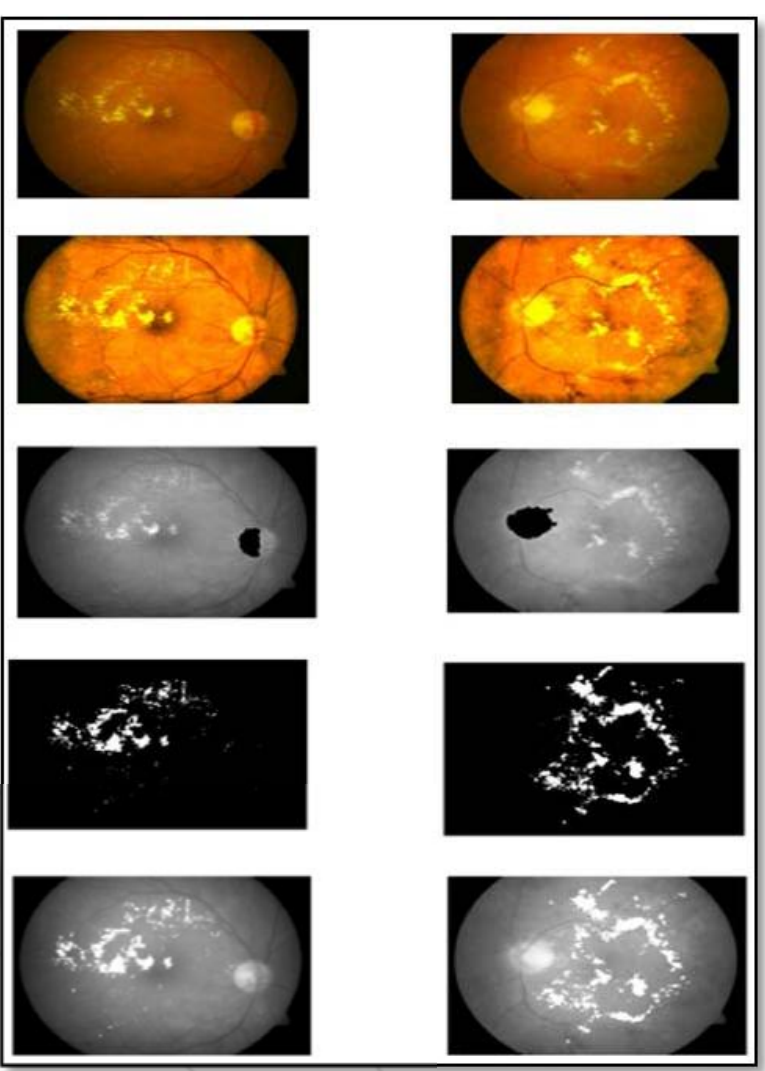

Figure 17: Exudates Detection: First row: Color retinal images; Second row: contrast enhanced RGB images; Third row: optic disk areas eliminated from the retinal images; Fourth row: exudate candidates after SWFCM; Fifth row: Results from third row superimposed on Intensity images [16]

The proposed algorithm for confining the optic disc works well even though the input retinal image is in a low contrast condition. The accuracy (92.53\%) measured well and specificity (98\%) was good.

However, the sensitivity (86\%) was on lower side and PPV, PLR values were not mentioned.

\subsection{Automatic Detection of Optic Disc And Exudates In Retinal Images}

In this paper [17], the proposed method by D. Kavitha et al. consists of three parts. Firstly, the blood vessels were segmented using median filtering and then, the convergent point (CP) of blood vessels were found using the least square fitting. Second part was to take out brighter regions using multilevel thresholding and finally, the third part was to combine both to establish the location of optic disc. The flow chart is given in figure 18 . 


\section{International Journal of Science and Research (IJSR) \\ ISSN (Online): 2319-7064}

Index Copernicus Value (2013): 6.14 | Impact Factor (2015): 6.391

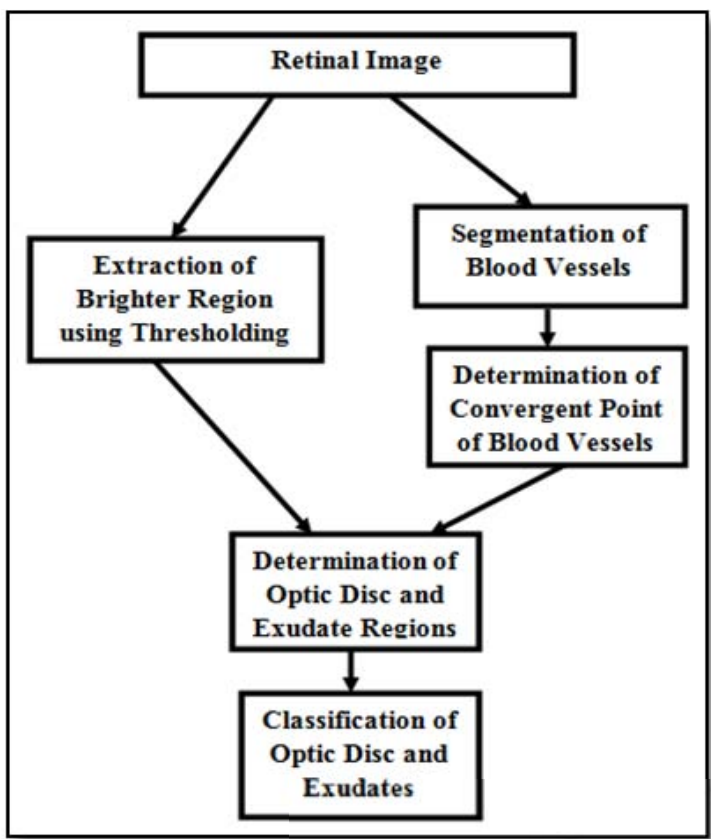

Figure 18: Retinal blood vessel segmentation method proposed by D. Kavitha et al. [17]

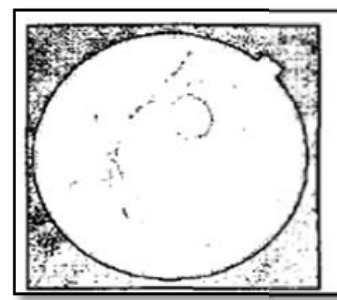

(a)

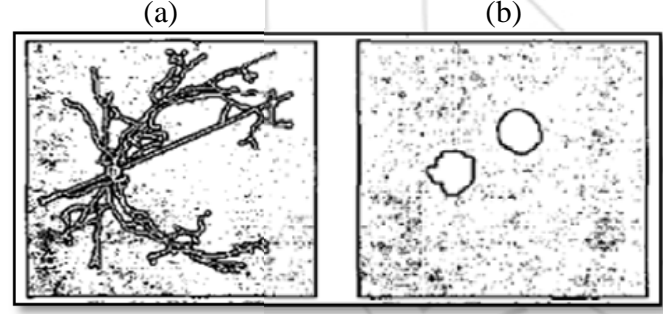

(c)

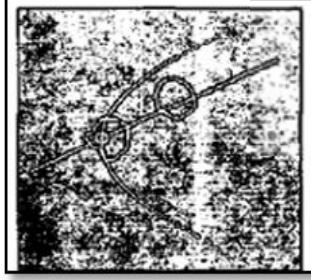

(e)

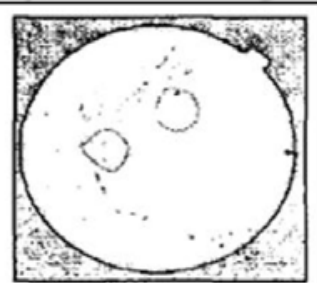

(b)

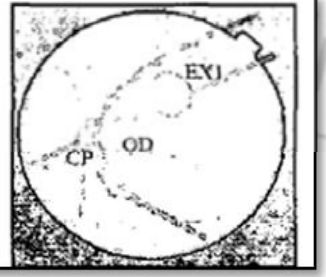

(f)
Figure 19: (a) Original image (b) Ground truth (c) BV and CP (d) Thresholded regions (e) CP with OD (f) Final result of abnormal retinal image [17]

This algorithm produced good accuracy (97.78\%) with respect to number of exudates but the accuracy was not considerable (84.56\%) with respect to area of exudates. Sensitivity was pretty high (100\%) with respect to number of exudates, but measured moderately (91.52\%) with respect to area of exudates. PPV measured very high (98.75\%) with respect to number of exudates, and was moderate (91.72\%) with respect to area of exudates.
However, in some images, optic disc edges were not sharp. Hence the boundaries between the ground truth optic disc and automatically detected optic disc could not be predicted accurately, hence that resulted in low accuracy and sensitivity. Apart from that, some images had over illumination at the edge of the retina. Here, Specificity and PLR values were not mentioned.

\subsection{Retinal image analysis using morphological process and clustering technique}

In this paper [18], R.Radha et al. have proposed the algorithm to combine multi structure morphological process.

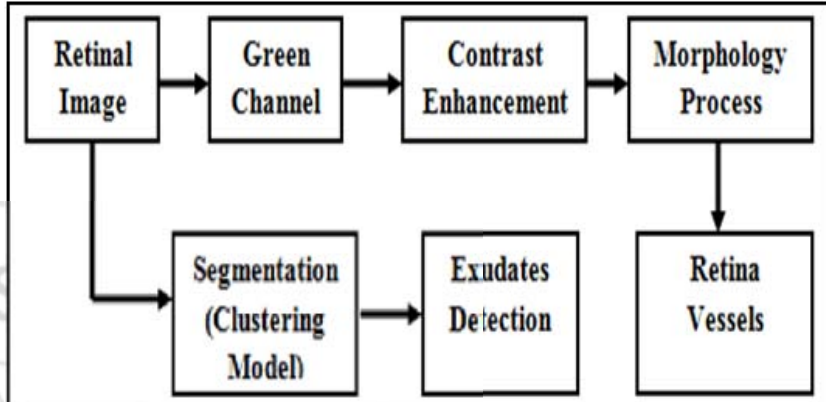

Figure 20: Block diagram of Retinal Image analysis proposed by R.Radha et al.[18]

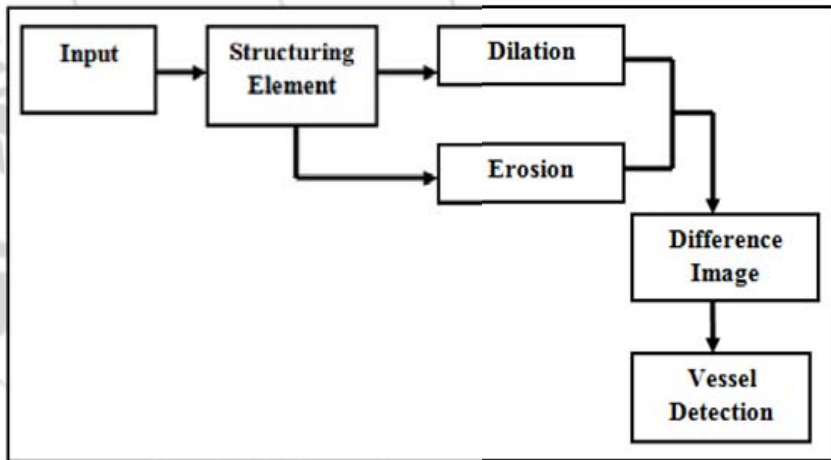

Figure 21: Flow diagram of vessel detection proposed by R.Radha et al. [18]

Here, segmentation technique was used efficiently to detect retinal vessel and exudates. Firstly, Retina Blood Vessels Detection was performed in which Plane separation, Contrast Enhancement, Morphological Process were done under this step. Secondly, segmentation Technique was used for exudates Detection. The image was taken first and converted the RGB image into grayscale image. Then, retinal blood vessels were extracted using bit plane separation, contrast enhancement and morphological process like dilation, erosion, closing and opening. Next, Discrete Wavelet transform (DWT) \& Energy feature coefficients were applied to extract feature. Then, the extracted features were taken for training with Probabilistic Neural Networks (PNN). After that, K-means Clustering method was applied to for segmentation which helped in differentiating the hard and soft exudates. Thus, it helped to determine whether the retina was in normal condition or not. The extracted exudates are shown in figure 22.

\section{Volume 5 Issue 4, April 2016




\section{International Journal of Science and Research (IJSR) \\ ISSN (Online): 2319-7064}

Index Copernicus Value (2013): 6.14 | Impact Factor (2015): 6.391

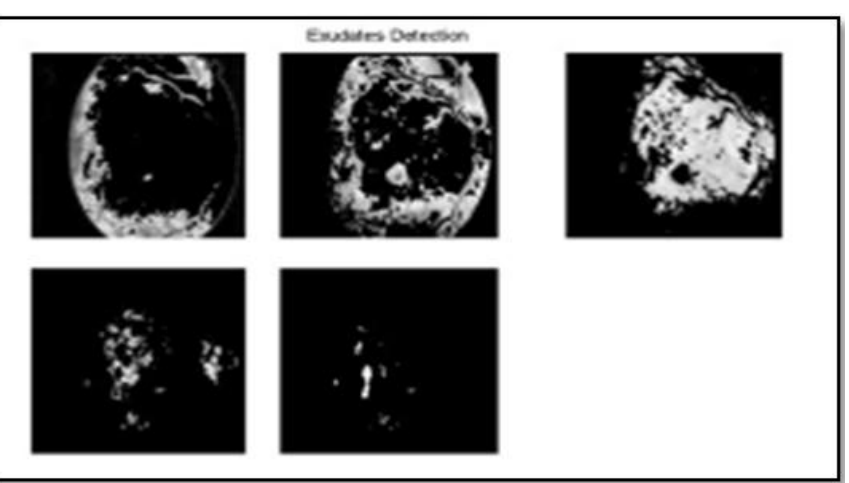

Figure 22: Extracted exudates [18]

Here, the Process time was faster than other clustering with more number of data points. 110 images were tested and trained for producing better result. It also provided better contrast enhancement, precise detection of retina vessel and execute. Blood vessel edges were identified effectively by using the structure elements morphology.

However, the disadvantage of the K-means clustering algorithm is: $\mathrm{K}$, the number of clusters must be determined; it does not yield the same result each time the algorithm is executed. Also, simple thresholding method was used, therefore, there was missing of some thin vessels. The author had not done quantitative analysis of the work based on the parameters like accuracy, recall, specificity.

4.10Automatic detection of optic disc and blood vessels from retinal images using Image processing technique

In this paper [11], Oakar Phyo et al. have proposed the following processes for Automatic detection of optic disc and blood vessels from retinal images:

Firstly, the image was taken in RGB format and it was then converted to HSI format, shown in figure 23.

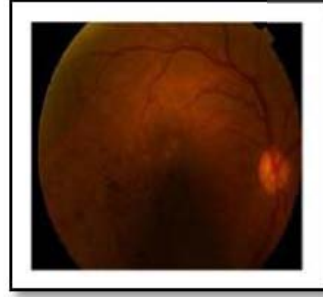

(a)

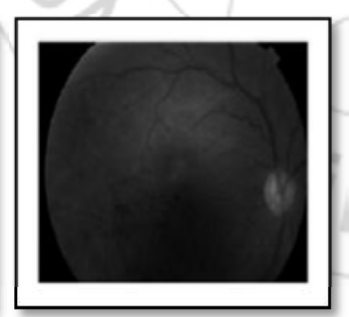

(b)
Figure 23: (a) Original RGB and (b) HSI images [11]

Then the image was filtered using median filtering. It can reduce the noise effect without blurring the edge of image.

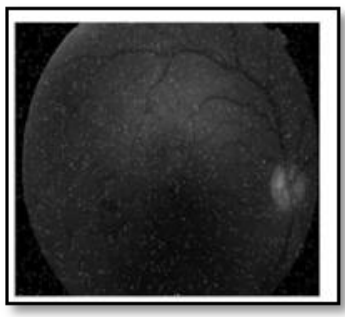

(a)

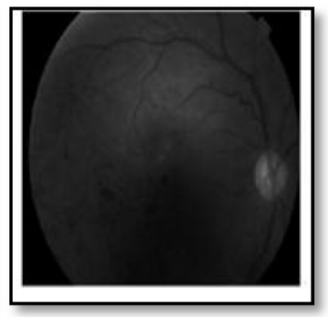

(b)
Figure 24: (a) Image with noise (b) Result of median filter
After that, the image was subjected to enhancement using histogram equalization technique which is shown in figure 25.

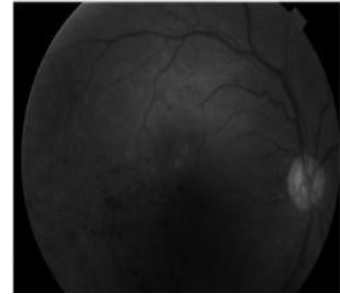

(a)

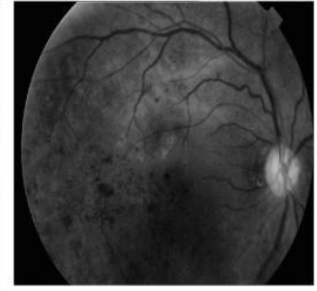

(b)
Figure 25: (a) Original image (b) Result of adaptive histogram equalization [11]

Secondly, the optic disc was detected. The flow chart for optic disc detection proposed by Oakar Phyo et al. [11] is shown in figure 26. For this purpose; this algorithm used mathematical morphology operators. Dilation, erosion, closing, opening are the basic functions which were used as morphological operators. In this case, the structuring element was chosen carefully. Then, the result image was binarized and reconstructed. Finally, The Otsu's thresholding technique was performed on the difference between original image and reconstructed image to detect the desired area of optic disc. Detection of optic disc is useful because it can reduce the detection of false positive of the exudates.

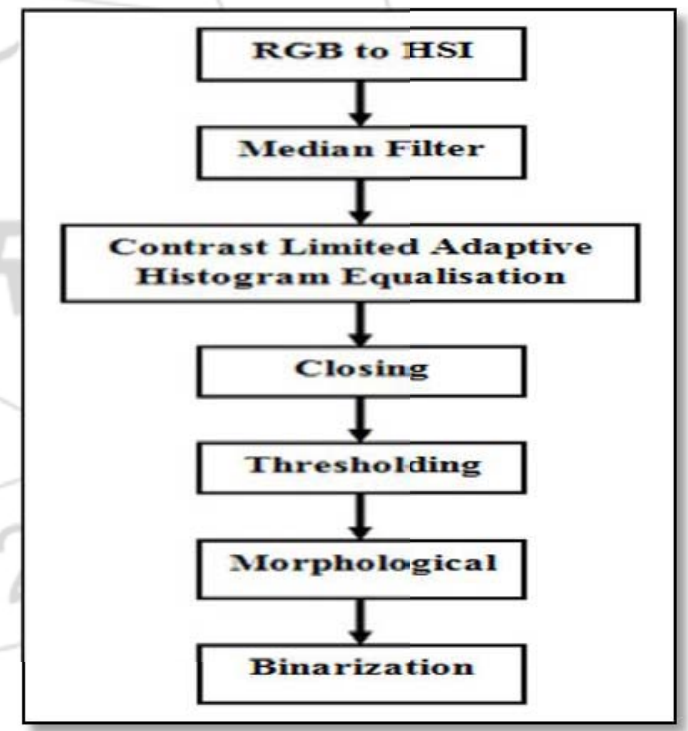

Figure 26: Flow diagram for optic disc detection proposed by Oakar Phyo et al. [11]

Finally, the blood vessels were detected. The procedural flow for detection of blood vessels proposed by Oakar Phyo et al. is given in figure 27. First the input image was converted into greyscale image to strengthen the exterior of the blood vessels. Then the median filtering was used for reducing the effect of noise and the CLAHE techniques was used for image enhancement purposes. Then, the same intensity values were closed using closing operator and the holes in the vessels were filled up using the filling operators. Finally, the Otsu's thresholding technique was applied to the difference between the closing and the filling images to detect the vessels area.

[11] 


\section{International Journal of Science and Research (IJSR) \\ ISSN (Online): 2319-7064}

Index Copernicus Value (2013): 6.14 | Impact Factor (2015): 6.391

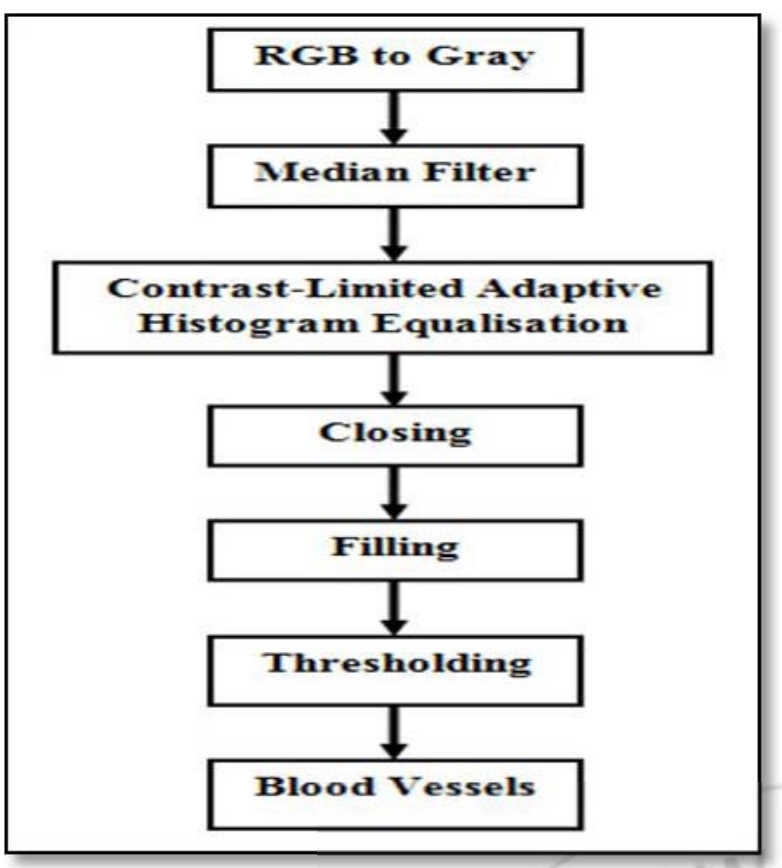

Figure 27: Flow chart for blood vessels detection proposed by Oakar Phyo et al. [11]

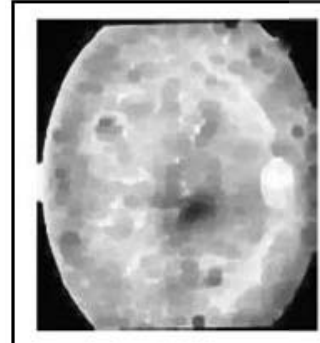

(a)

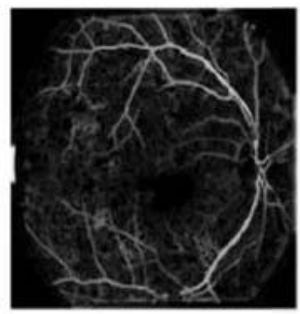

(c)

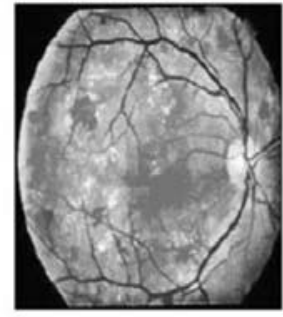

(b)

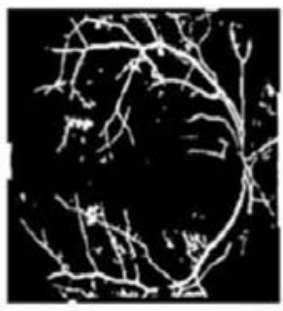

(d)

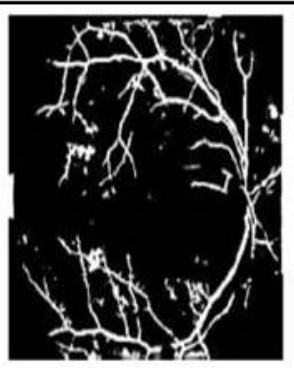

(e)

Figure 28: (a) Closing (b) Filling (c) Difference (d) Thresholding (e) Detected Blood Vessels [11]

This paper used mathematical morphology on the fundus images because morphological operators work very fast and require lower computing power. Thus, this algorithm was very efficient in detecting blood vessels. However, the author has not done quantitative analysis of the work based on the parameters like accuracy, recall, specificity.

\section{Comparative Study of these works}

We have taken 10 papers to study the process for automatic blood vessel detection in retinal images. Below is the comparative study between them based on different parameters.

Table 1: Comparison between the papers based on different parameters

\begin{tabular}{|c|c|c|c|c|c|c|c|c|}
\hline \multirow{2}{*}{$\begin{array}{l}\mathrm{Sl} \\
\mathrm{No}\end{array}$} & \multirow[t]{2}{*}{ Paper Name } & \multirow[t]{2}{*}{ Author Name } & \multicolumn{6}{|c|}{ Parameter } \\
\hline & & & $\begin{array}{c}\text { Segmentation } \\
\text { Technique }\end{array}$ & Accuracy & \begin{tabular}{|c|} 
Recall/ \\
Sensitivity
\end{tabular} & Specificity & \begin{tabular}{|c|}
$P P V$ (Positive \\
Predictive \\
Value) \\
\end{tabular} & $\begin{array}{c}\text { PLR (Positive } \\
\text { Likelihood } \\
\text { Ratio) } \\
\end{array}$ \\
\hline 1 & $\begin{array}{c}\text { FCM based blood vessel } \\
\text { segmentation method for retinal } \\
\text { image }\end{array}$ & $\begin{array}{c}\text { Nilanjan Dey } \\
\text { et al. [5] }\end{array}$ & Fuzzy C Means & $95.03 \%$. & $99.62 \%$. & $54.66 \%$. & $95.08 \%$. & $219.72 \%$ \\
\hline 2 & $\begin{array}{l}\text { Automatic detection of diabetic } \\
\text { retinopathy exudates from non- } \\
\text { dilated retinal images using } \\
\text { mathematical morphology } \\
\text { methods }\end{array}$ & \begin{tabular}{|c|} 
Akara \\
Sopharak et al. \\
{$[12]$}
\end{tabular} & Fuzzy C Means & 96.79 & 80 & 99.46 & 68.56 & 54.92 \\
\hline 3 & $\begin{array}{l}\text { Automatic Exudate Detection } \\
\text { from Non-dilated Diabetic } \\
\text { Retinopathy Retinal Images Using } \\
\text { Fuzzy C means Clustering }\end{array}$ & \begin{tabular}{|c|} 
Akara \\
Sopharak et al. \\
{$[13]$}
\end{tabular} & Fuzzy C Means & 99.11 & 87.28 & 99.24 & 42.77 & 224.26 \\
\hline
\end{tabular}

Volume 5 Issue 4, April 2016

www.ijsr.net 


\section{International Journal of Science and Research (IJSR) \\ ISSN (Online): 2319-7064}

Index Copernicus Value (2013): 6.14 | Impact Factor (2015): 6.391

\begin{tabular}{|c|c|c|c|c|c|c|c|c|}
\hline 4 & $\begin{array}{c}\text { A Novel Retinal Blood Vessel } \\
\text { Segmentation Algorithm using } \\
\text { Fuzzy segmentation }\end{array}$ & $\begin{array}{c}\text { Razieh } \\
\text { Akhavan et al. } \\
{[14]}\end{array}$ & Fuzzy C Means & $\begin{array}{l}72.52 \\
\text { (Drive) } \\
77.66 \\
\text { (Stare) }\end{array}$ & $\begin{array}{c}97.33 \\
\text { (Drive) } \\
96.80 \\
\text { (Stare) }\end{array}$ & $\begin{array}{l}95.13 \\
\text { (Drive) } \\
95.37 \\
\text { (Stare) }\end{array}$ & $\begin{array}{l}\text { Not } \\
\text { mentioned }\end{array}$ & Not mentioned \\
\hline 5 & $\begin{array}{c}\text { A Contribution of Image } \\
\text { Processing to the Diagnosis of } \\
\text { Diabetic Retinopathy-Detection } \\
\text { of Exudates in Color Fundus } \\
\text { Images of the Human Retina } \\
\end{array}$ & $\begin{array}{c}\text { Thomas } \\
\text { Walter et al. } \\
{[1]}\end{array}$ & Fuzzy C Means & $\begin{array}{c}\text { Not } \\
\text { mentioned }\end{array}$ & $92.80 \%$ & $\begin{array}{c}\text { Not } \\
\text { mentioned }\end{array}$ & $92.4 \%$. & Not mentioned \\
\hline 6 & $\begin{array}{l}\text { Automatic exudate detection for } \\
\text { diabetic retinopathy screening }\end{array}$ & \begin{tabular}{|c|} 
Akara \\
Sopharak et al. \\
{$[15]$}
\end{tabular} & $\begin{array}{l}\text { Improved FCM } \\
\text { (IFCM) }\end{array}$ & $\begin{array}{c}\text { Not } \\
\text { mentioned }\end{array}$ & 97.29 & 85.43 & $\begin{array}{l}\text { Too many } \\
\text { values for } \\
\text { different } \\
\text { conditions }\end{array}$ & $\begin{array}{l}\text { Too many } \\
\text { values for } \\
\text { different } \\
\text { conditions }\end{array}$ \\
\hline 7 & $\begin{array}{l}\text { Segmentation of Exudates and } \\
\text { Optic Disc in Retinal Images }\end{array}$ & $\begin{array}{c}\text { Giri Babu } \\
\text { Kande et al. } \\
{[16]} \\
\end{array}$ & $\begin{array}{l}\text { Spatially Weighted } \\
\text { Fuzzy c-Means } \\
\text { clustering algorithm } \\
\end{array}$ & 92.53 & 86 & 98 & $\begin{array}{c}\text { Not } \\
\text { mentioned }\end{array}$ & Not mentioned \\
\hline 8 & $\begin{array}{c}\text { Automatic Detection Of Optic } \\
\text { Disc And Exudates In Retinal } \\
\text { Images }\end{array}$ & $\begin{array}{l}\text { D. Kavitha et } \\
\text { al. [17] }\end{array}$ & \begin{tabular}{|c|} 
Segment the blood \\
vessels using median \\
filtering and find the \\
convergent point $(\mathrm{CP})$ \\
of blood vessels using \\
the least square fitting \\
\end{tabular} & \begin{tabular}{|l} 
Area of \\
exudates: \\
84.56 \\
Number: \\
97.78 \\
\end{tabular} & $\begin{array}{l}\text { Area: } \\
91.52 \\
\text { Number: } \\
100.00\end{array}$ & $\begin{array}{c}\text { Not } \\
\text { mentioned }\end{array}$ & $\begin{array}{l}\text { Area: } 91.72 \\
\text { Number: } \\
98.75\end{array}$ & Not mentioned \\
\hline 9 & $\begin{array}{l}\text { Retinal image analysis using } \\
\text { morphological process and } \\
\text { clustering technique }\end{array}$ & $\begin{array}{c}\text { R.Radha et al. } \\
\text { [18] }\end{array}$ & K means Clustering & $\begin{array}{c}\text { Not } \\
\text { mentioned }\end{array}$ & $\begin{array}{c}\text { Not } \\
\text { mentioned }\end{array}$ & $\begin{array}{c}\text { Not } \\
\text { mentioned }\end{array}$ & $\begin{array}{c}\text { Not } \\
\text { mentioned }\end{array}$ & Not mentioned \\
\hline 10 & $\begin{array}{c}\text { Automatic detection of optic disc } \\
\text { and blood vessels from retinal } \\
\text { images using Image processing } \\
\text { technique }\end{array}$ & $\begin{array}{c}\text { Oakar Phyo et } \\
\text { al. [11] }\end{array}$ & $\begin{array}{c}\text { Mathematical } \\
\text { morphology }\end{array}$ & $\begin{array}{c}\text { Not } \\
\text { mentioned }\end{array}$ & $\begin{array}{c}\text { Not } \\
\text { mentioned }\end{array}$ & $\begin{array}{c}\text { Not } \\
\text { mentioned }\end{array}$ & $\begin{array}{l}\text { Not } \\
\text { mentioned }\end{array}$ & Not mentioned \\
\hline
\end{tabular}

\section{Graphical analysis}

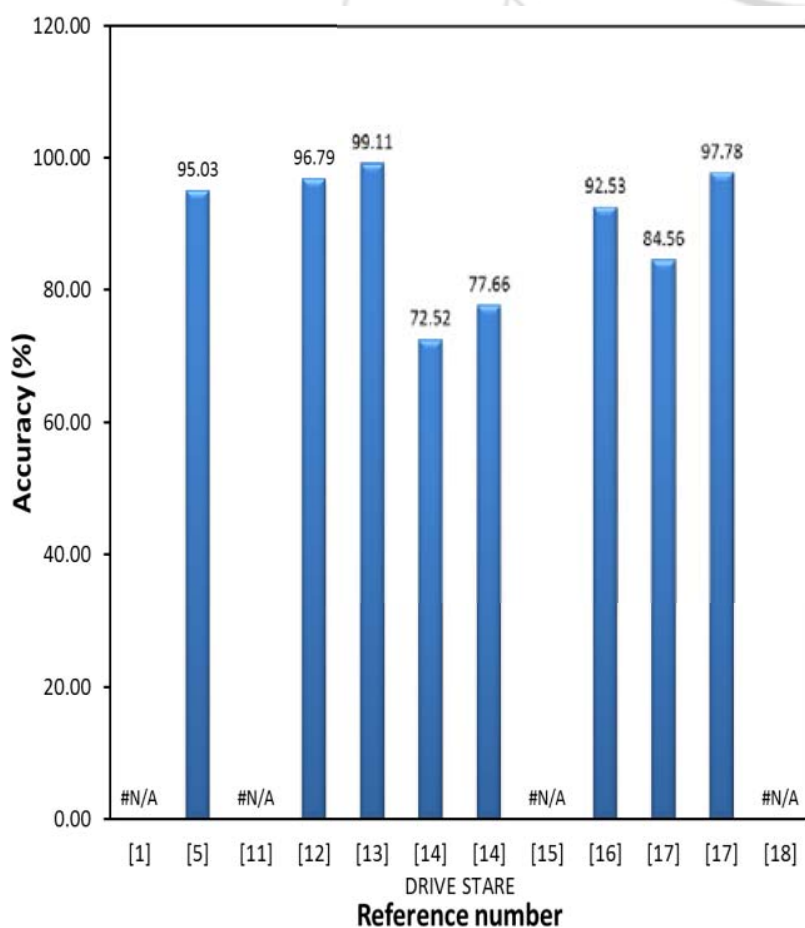

Figure 29: Graphical analysis of the works with respect to Accuracy

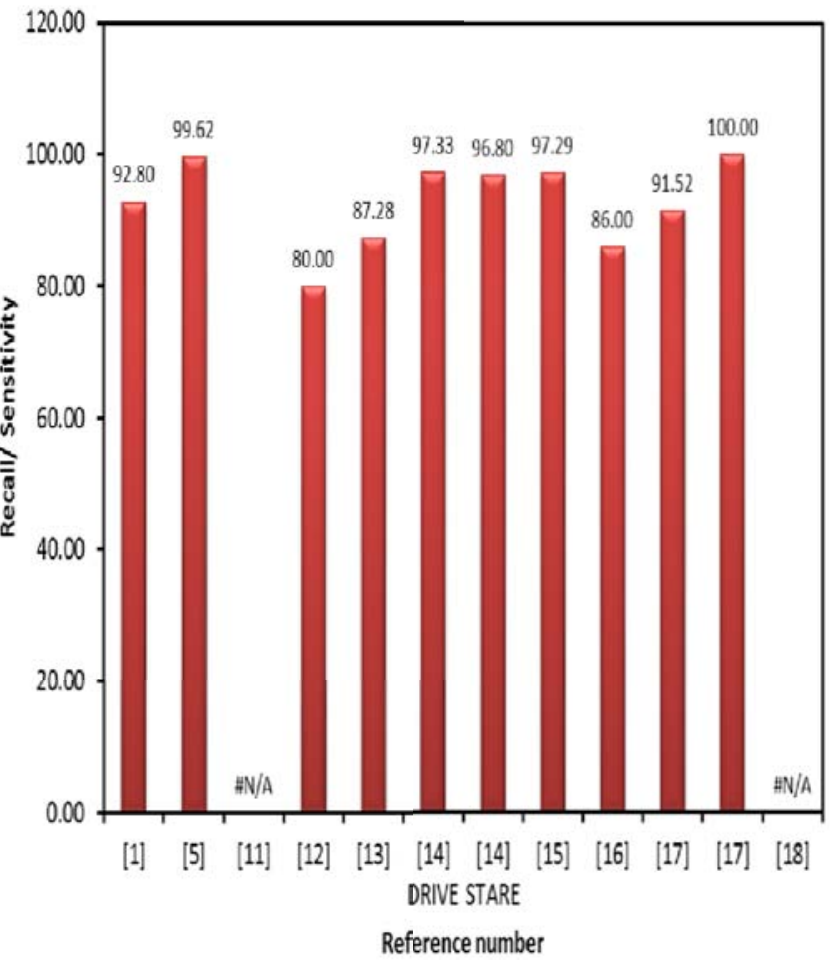

Figure 30: Graphical analysis of the works with respect to Sensitivity 


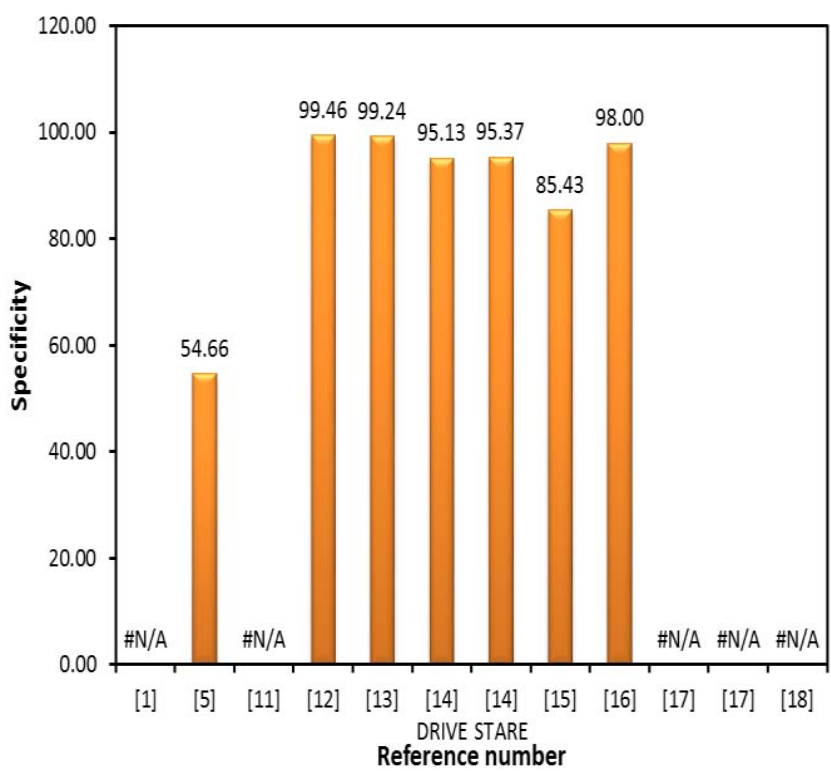

Figure 31: Graphical analysis of the works with respect to Specificity

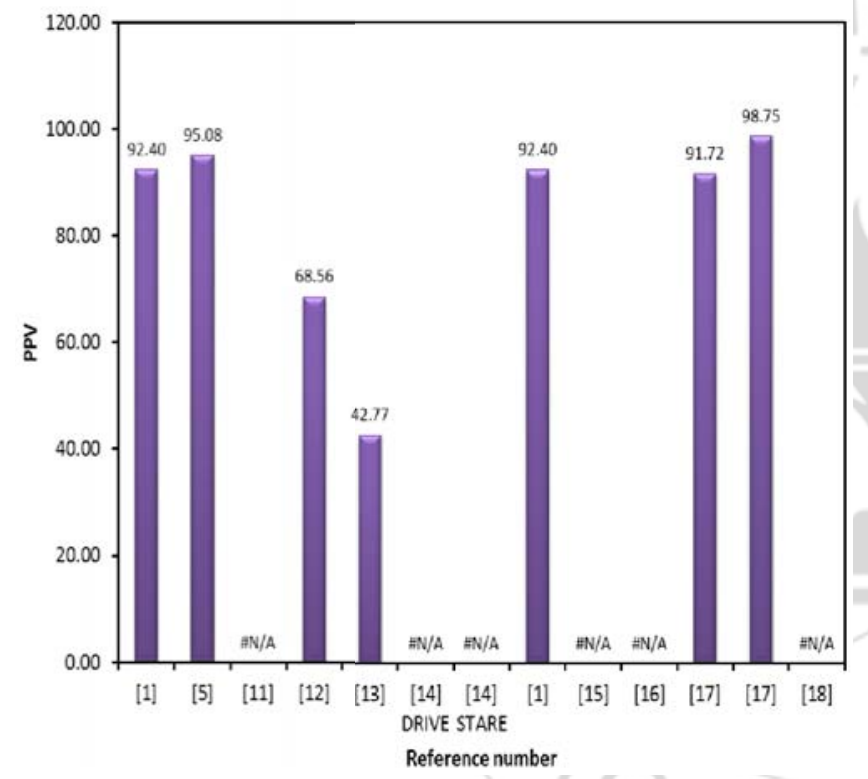

Figure 32: Graphical analysis of the works with respect to PPV

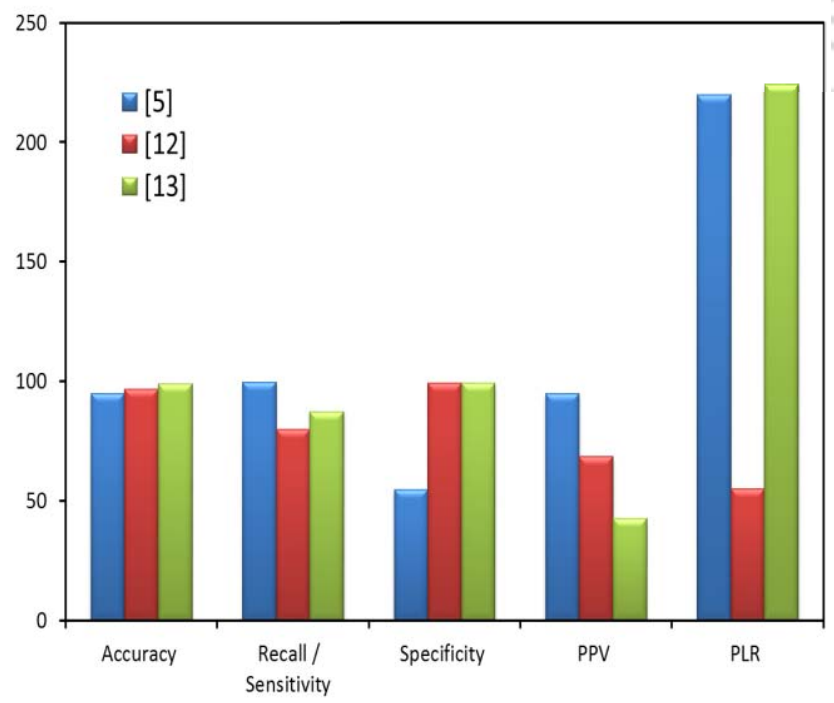

Figure 33: Comparison of parameters between references [5], [12] and [13]
Based on 10 papers studied, paper [5], [12] and [13] have done all the quantitative analysis efficiently. These 3 algorithms used Fuzzy C means clustering method. In paper [13], the work yielded higher accuracy, specificity and PLR, but lower sensitivity. On the contrary, in paper [5], accuracy, sensitivity, PPV and PLR are on higher side but it has comparatively lesser specificity. Figure 33 is the graphical representation of different parameters that have been measured in those papers.

\section{Conclusion}

Diabetic retinopathy is a diabetes complication, which has adverse effects on eyes. It's caused by damage to the blood vessels of the light-sensitive tissue at the back of the eye (retina) i.e. fundus. Therefore, early detection of abnormal blood vessels in fundus is required to protect the vision of eyes. Image processing of color fundus images has the prospective to play a key role in diagnosis of diabetic retinopathy. Of late, ophthalmologists detect the abnormal lesions using hand drawn ground truth. However, this is prone to human error. Therefore, robustness, efficiency and accuracy have been evaluated on a small image database to precisely detect abnormal blood vessels. The input images for algorithm to detect and segment abnormal blood vessels from retinal images should be good quality in terms of sharpness, contrast, focus etc. for proper segmentation. The performance of the algorithm is measured against ophthalmologists' hand-drawn ground-truth. The true positive, true negative, false positive and false negative values are measured and based on those values, Sensitivity, specificity, PPV, PLR and sensitivity are used as the performance measurement of blood vessel detection.

The future work will involve replacing the simple threshold method with a more proper approach to increase the accuracy and efficiency of this method. The improvisation needs to be done to deal with the problem of the presence of severe lesions in retinal fundus images. In addition, future work will address improvement of the performance of this system by improving the robustness of optic disc and blood vessel detection and finding more detailed characteristics of exudates, which could differentiate between hard and soft exudates more effectively.

\section{References}

[1] Thomas Walter, Jean-Claude Klein, Pascale Massin, Ali Erginay, -AContribution of Image Processing to the Diagnosis of Diabetic Retinopathy-Detection of Exudates in Color Fundus Images of the Human Retina", IEEE transactions on medical imaging, vol. 21, no. 10, october 2002

[2] F. Zana, -Ua Approche Morphologique Pour les Détections et Bayesienne Pour le Recalage d'Images Multimodales: Application aux Images Rétiniennes,", Ecole Nationale Supérieure des Mines de Paris, Centre de Morphologie Mathématique, Paris, France, 1999.

[3] A. Pinz, M. Prantl, and P. Datlinger, -Mapping the human retina," IEEE Trans. Med. Imag., vol. 1, pp. 210-215, Jan. 1998 


\section{International Journal of Science and Research (IJSR) \\ ISSN (Online): 2319-7064}

Index Copernicus Value (2013): 6.14 | Impact Factor (2015): 6.391

[4] F. Z. and J.-C. Klein, -Amulti-modal segmentation algorithm of eye fundus images using vessel detection and hough transform," IEEE Trans. Med. Imag., vol. 18, May 1999

[5] Nilanjan Dey, Anamitra Bardhan Roy, Moumita Pal, Achintya Das, -FCMbased blood vessel segmentation method for retinal image", International Journal of Computer Science and Network (IJCSN),Volume 1, Issue 3, June 2012,ISSN 2277-5420

[6] Research Section, Digital Retinal Image for Vessel Extraction (DRIVE) Database. Utrecht, The Netherlands, Univ. Med. Center Utrecht, Image Sci. Inst. [Online]. Available: http://www.isi.uu.nl/Research/Databases/DRIVE

[7] STARE Project Website. Clemson, SC, Clemson Univ. [Online]. Available: http://www.ces.clemson.edu/ ahoover/stare/ /

[8] X. Merlin Sheeba, S. Vasanthi, -AnEfficient ELM Approach for Blood Vessel Segmentation in Retinal Images," Bonfring International Journal of Man Machine Interface, Vol. 1, Special Issue, December 2011

[9] A. Hoover, V. Kouznetsova, and M. Goldbaum, -Locatig blood vessels in retinal images by piecewise threshold probing of a matched filter response," IEEE Trans. Med. Imag., vol. 19, no. 3, pp. 203-210, Mar. 2000.

[10] Muhammad Moazam Fraz , Paolo Remagnino, Andreas Hoppe, Bunyarit Uyyanonvara, Alicja R. Rudnicka, Christopher G. Owen, and Sarah A. Barman, -An Ensemble Classification-Based Approach Applied to Retinal Blood Vessel Segmentation," ieee transactions on biomedical engineering, vol. 59, no. 9, september 2012

[11] Oakar Phyo, Aung Soe Khaing, - Atomatic detection of optic disc and blood vessels from retinal images using Image processing technique", IJRET: International Journal of Research in Engineering and Technology eISSN: 2319-1163 | pISSN: 2321-7308

[12] Akara Sopharak a, Bunyarit Uyyanonvara a, Sarah Barmanb, Thomas H. Williamson c, -Atomatic detection of diabetic retinopathy exudates from nondilated retinal images using mathematical morphology methods", Computerized Medical Imaging and Graphics Volume 32, Issue 8, December 2008, Pages 720-727

[13]Akara Sopharak , Bunyarit Uyyanonvara, Sarah Barman, -Atomatic Exudate Detection from Nondilated Diabetic Retinopathy Retinal Images Using Fuzzy C means Clustering”, Sensors 2009, 9(3), 21482161; doi:10.3390/s90302148

[14] Razieh Akhavan, Karim Faez, -ANovel Retinal Blood Vessel Segmentation Algorithm using Fuzzy segmentation", International Journal of Electrical and Computer Engineering (IJECE) Vol. 4, No. 4, August 2014, pp. 561 572 ISSN: 2088-8708

[15] Akara Sopharaka, Bunyarit Uyyanonvaraa, Sarah Barman, - Atomatic exudate detection for diabetic retinopathy screening", doi: 10.2306/scienceasia15131874.2009.35.080

[16] Giri Babu Kande, P.Venkata Subbaiah, T.Satya Savithri, -Segrentation of Exudates and Optic Disc in Retinal Images", DOI: 10.1109/ICVGIP.2008.36 Publisher:
IEEE E-ISBN : 978-0-7695-3476-3 Date of Conference: 16-19 Dec. 2008 Page(s): 535 - 542

[17]D. Kavitha. S. Shenbaga Devi, -Atomatic Detection Of Optic Disc And Exudates In Retinal Images", DOI: 10.1109/ICISIP.2005.1529506, Publisher: IEEE, Print ISBN: 0-7803-8840-2, Date of Conference: 4-7 Jan. 2005, Date of Conference: 4-7 Jan. 2005

[18]R. Radha and Bijee Lakshman, - Rtinal image analysis using morphological process and clustering technique", SIPIJ Vol.4, No.6, December 2013

\section{Author Profile}

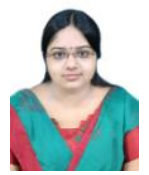

Shreyasi Hazra received her B.Tech degree in Electronics and Communication Engineering from JIS College of Engineering under West Bengal University of Technology in 2012. She has worked with IBM as Application Developer for 1 year and 8 months. Currently, she is pursuing her M.Tech in Electronics and Communication from Institute of Engineering \& Management under same university. Her area of interest includes image processing \& analysis.

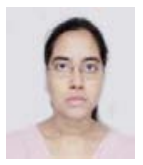

Atashi Patra has completed her B.Tech in Electronics and Communication Engineering from Asansol Engineering College under West Bengal University of Technology in 2013. Currently, she is pursuing her M.Tech in Electronics and Communication from Institute of Engineering \& Management under same university. Her area of interest is in image processing \& analysis.

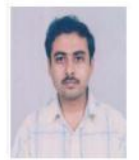

Tuhin Utsab Paul did his undergraduate and post graduate degrees in computer science and engineering from the University of Calcutta. He is working as an assistant professor in the department of electronics and communication at the Institute of Engineering and Management since 2012. His research area includes bio - medical image processing, digital signal processing and embedded system design. 